\title{
Electrical Loading Assessment of Check for
updates Commonly-Used Transformers for Feeder 21 of Pampanga Distribution Utility
}

\author{
Reynaldo H. Gomez Jr., Edgardo M. Santos, Armie C. Tolentino, Eldren V. Bulanan, Noel T. \\ Florencondia
}

\begin{abstract}
Transformer plays a vital part in the process of utilization of electricity. In power distribution, the most widely used equipment is the distribution transformer (DT) and function to transform the primary voltage of 13200 volts to the utilization level voltage of 230 volts. In a distribution system, transformers are installed serving commercial, industrial, irrigation, street lights and residential consumers. Distribution transformers were classified as sole-used and commonly-used distribution transformers. The study focuses on assessing the commonly-used distribution transformer of Feeder 21 of Pampanga Distribution Utility. Microsoft Excel 2013 was used to evaluate the percent loading, core and copper losses of each DT's installed in the feeder. The DTs were classified according to their percent loading: Overloaded Above 71\%, Normal Loaded $40 \%$ to $70 \%$, and Under Loaded Below 40\%. From the data from 2017-2018, 104 units commonly-used DT's were installed in the feeder. From the results obtained, 30 units were overloaded distribution transformers while 31 units were under loaded distribution transformers. Out of 104 distribution transformers 61 of which are not in the normal loading conditions. The total Core loss in MWh of the distribution transformer in under loaded and overloaded conditions were 34.37 and 38.04, while the copper loss in under loaded and overloaded conditions was 7.46 MWh and 199.76 MWh respectively. The study also shows the implication if the percent loading was maintained to $70 \%, 110.21 \mathrm{MWh}$ will be saved by the electric utility. The researchers find that there is a need in uprating or downrating of transformer and quantifying the consumer connected in each distribution transformers for proper transformer loading may be considered by the Distribution Utility.
\end{abstract}

Keywords: Commonly-Used Distribution Transformer, Copper Loss, Core Loss, Percent Loading.

Revised Manuscript Received on December 30, 2019.

* Correspondence Author

Reynaldo H. Gomez Jr.*, Electrical Engineering Department, Don Honorio Ventura State University, Bacolor, Pampanga, Philippines. Email: iieered17@yahoo.com.ph

Edgardo M. Santos., Electrical Engineering Department, Don Honorio Ventura State University, Bacolor, Pampanga, Philippines. Email: edgardomsantos@yahoo.com

Armie C. Tolentino., Electrical Engineering Department, Don Honorio Ventura State University, Bacolor, Pampanga, Philippines. Email: anc@gmail.com

Eldren V. Bulanan., Human Resources and Development Department, Pampanga I Electric Cooperative, Mexico, Pampanga, Philippines. Email: el_dren30@yahoo.com

Noel T. Florencondia., Graduate School Department, Nueva Ecija University of Science and Technology, Cabanatuan, Nueva Ecija, Philippines. Email: florencondia61@gmail.com

(C) The Authors. Published by Blue Eyes Intelligence Engineering and Sciences Publication (BEIESP). This is an open access article under the CC BY-NC-ND license (http://creativecommons.org/licenses/by-nc-nd/4.0/)

\section{INTRODUCTION}

Electricity is a necessity in today's modern world. Before people can utilize electricity, it will pass a series of the process these are generation, transmission, and distribution. Electric distribution utilities do distribution of electricity. Each distribution utilities must ensure the power quality in their distribution system, and it must operate in safe, efficient, and with a high degree of reliability [1]. System reliability and efficiency are very vital in today's operation to all-electric utilities because of the fact that they can be ranked and can generate income for growth. One part of the system that contributes to its reliability and efficiency that taken into account is the transformer[2]. In a typical power system, it uses two kinds of a transformer, the step up and step down transformer[3]. Step-up transformer has fewer turns of primary winding than the secondary winding and they were commonly used of transmission system or the National Grid Corporation of the Philippines (NGCP) while step down transformers has more turns in the primary winding rather than its secondary and usually use in the distribution system or Electric Utilities. In power distribution, distribution transformers (DT) function is to transform the primary distribution voltage of 13200 volts to the utilization level voltage of 230 volts. To perform this function, these must be located as close as practicable to the load. DT's can be found in almost anywhere imaginable mounted on poles, on platforms, on concrete pads, or installed in indoor vaults. Also, in the distribution, DT's are categorized to sole-used distribution transformer were only one consumer or $\mathrm{kWh}$ meter is installed and commonly-used distribution transformer, which multiple numbers of consumer or multiple kWh meter are installed which are mostly residential consumers. To attain the appropriate utilization of a transformer, percent loading is critical; every electric utility attempt to maintain the percent loading of $40-70 \%$ of the rated capacity and its efficiency is will be maximum when loaded in nearly $50 \%$ of the nominal rating. [4]. Even though they have high efficiency, DT's is the one that contributes significant system loss in the power system. These losses can also play an important part in the status of the distribution of the transformer [5]. Transformer losses were classified into two components, which are characteristics of the physical construction of the transformer. One component of transformer losses are determined by the quality of the steel used in the transformer core is called core loss or no-load loss.

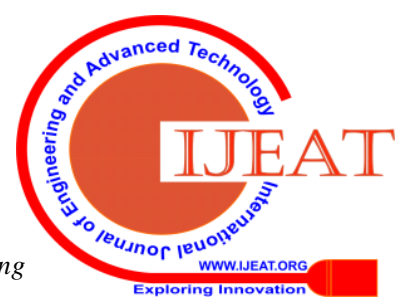


Once the DT is energized, and even its load varies, core loss would be constant. The other component is called copper loss or load losses, and it varies as the square of the current flowing through the transformer coils. The copper losses are dependent upon the loading of the transformer and are difficult to compute individually when numerous units are involved. [6]. With this, transformer loading should be monitored to prevent transformers from becoming extremely overloaded for a significant period which could lead to burning out or worse, catastrophic failure [7-8]. The overloaded transformer can increase its copper loss and can affect its useful life [9], while on the other hand, in under load state copper loss decrease. Under loaded transformers do not maximize its use and contribute more considerable core loss [10].

An effective transformer load monitoring system takes into account the transformer-costumer connectivity and transformer data such as rating, connection, and location. Transformer loading conditions are important to identify the situation of the distribution transformer. Monitoring of it can help the utility to maintain the operation of the transformer [11-12].

One of the electric distribution utilities in Pampanga supplies electricity to the towns of Arayat, Sta. Ana, Candaba, San Luis, Mexico, and Magalang. Seven substations located at Sto Domingo Mexico, Lagundi, San Nicolas Magalang, San Isidro Magalang (not-energized), Sta. Monica San Luis, Pandacaqui and PlazangLumaArayat. Each of the substations is divided into feeders, Sto. Domingo Substation feeders are 11, 12, 13, 14, Lagundi Substation are feeders 71, 72, 73, San Nicolas Substation feeders are 61, 62, 63, Sta Monica Substation are feeders 51, 52, 53, Pandacaqui Substation feeders are 31, 32, 33 and PlazangLuma Substation feeders are 21, 22, 23 as shown in Figure 1.



Figure 1: Map of Pampanga Distribution Utility and Substation Locations

Each of the feeders I serves different types of consumer which are commercial, industrial, irrigation, industrial, street lights and residential. In Figure 2, the numbers of residential consumer per feeder as of December 2018 were presented.

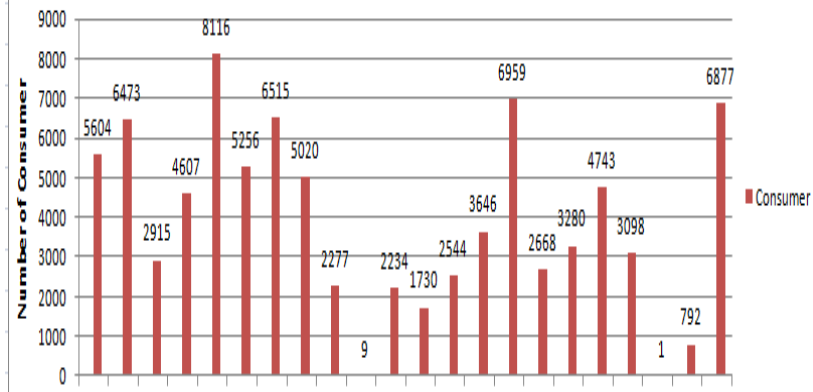

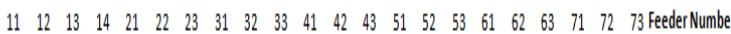

Figure 2: Number of Consumer per Feeder

The residential consumers were connected to a distribution transformer called commonly-used distribution transformer, number of commonly-used DT's as of December 2018 are shown in the figure 3 .

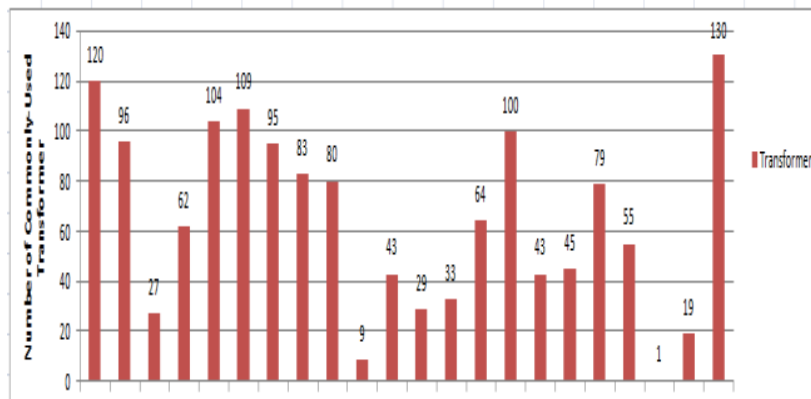

$\begin{array}{llllllllllllllllllllll}11 & 12 & 13 & 14 & 21 & 22 & 23 & 31 & 32 & 33 & 41 & 42 & 43 & 51 & 52 & 53 & 61 & 62 & 63 & 71 & 72 & 73 \text { Feder }\end{array}$

\section{Figure 3: Number of Commonly-Used Distribution Transformers}

From figure 2, Feeder 21 is one of the large feeders in terms of residential consumers, serving 8116 residential consumers. In the number of commonly-used DT's, Feeder 21 is the $4^{\text {th }}$ that has over 100 DT's installed as indicated in figure 3. As of December 2018, from 104 DT's installed in the feeder, 2units of 10kVA, 10units of 15kVA, 39 units of $25 \mathrm{kVA}$, 24units of $37.5 \mathrm{kVA}$, 24units of $50 \mathrm{kVA}$, 5units of $75 \mathrm{kVA}$ were used as seen in figure 4. From January 2017 to December 2018, several power outages due to reported distribution transformer failure have experienced as shown in figure 5. Causes of this transformer failure were busted transformer and busted fuse link due to overloading. In the months of March, April, and May an increasing trend of power outages occur due to dry seasons which a higher demand for electricity. Transformer failure may affect the duration of the interruption as seen in figure 6 . In figure 7 , the number of consumers affected of the interruption due to transformer failure is also increasing specially from the months of March to May. Without proper management of the transformer loading, power outages will always occur [13].

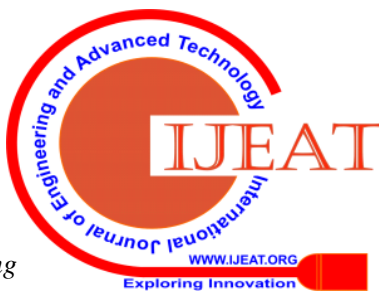




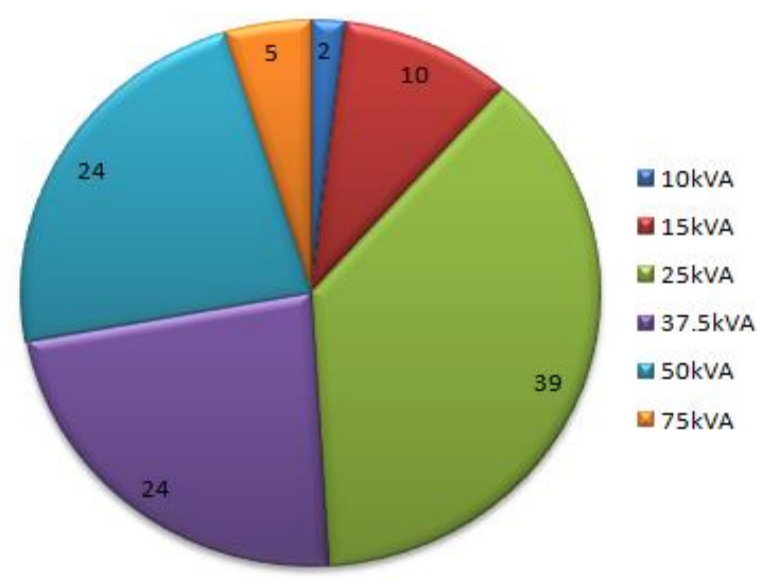

Figure 4: Number of Commonly-Used Transformer of Feeder 21



Figure 5: Number of Interruption

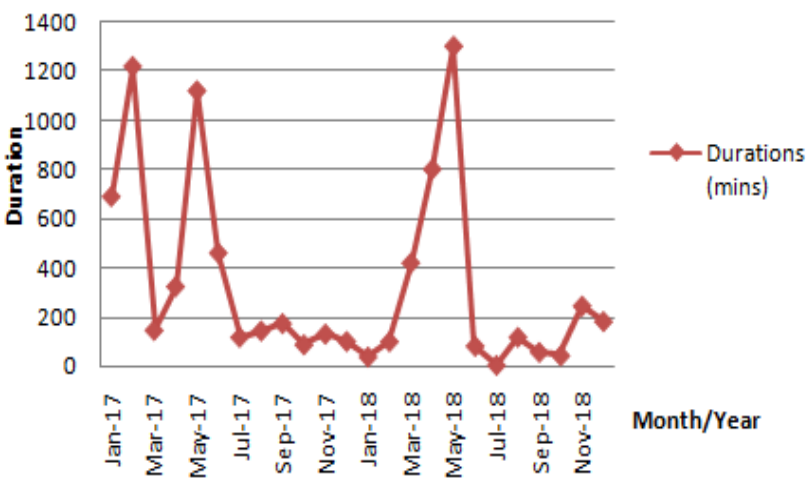

Figure 6: Duration of Interruption

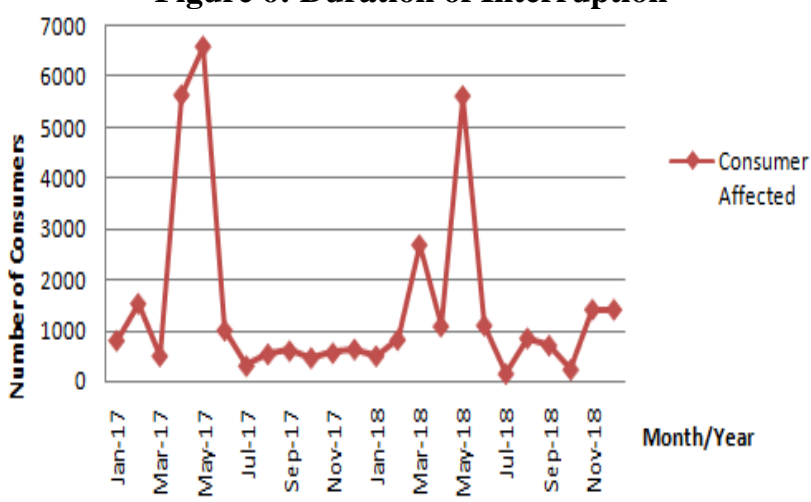

Figure 7: Number of Consumer affected from Interruption

Distribution Utilities were driven to improve its distribution system to supply reliable and efficient electricity for its consumers. The power interruption due to distribution transformer failure in Feeder 21 was increasing specially at the months of March, April and May which the demand of electricity is high. Does the condition of the present percent loading of the commonly-used distribution transformer of Feeder 21 was still in normal loading conditions? In terms of $\mathrm{kWh}$, how does the percent loading condition of the DT's will affect the copper and core losses of the feeder? And if the percent loading is maintained to $70 \%$ loading, can it beneficial for the utility in terms of $\mathrm{kWh}$ ?

With this, the objective of the study is to identify the present loading condition of commonly-used distribution transformer for Feeder 21 of Pampanga Distribution Utility. To categorize the DT's to loading condition such as a.) Over Loaded b.) Normal Loaded c.) Under Loaded: to analyze the effects of percent loading in the system loss of the feeder [4]. Also, to determine the effects of the loading conditions under the overloaded and under loaded in terms of $\mathrm{kWh}$ for copper and core loss, and to compare the copper loss if the percent loading is maintained to $70 \%$.

This will help the utility personnel to be aware of the present conditions of the DT's installed in the feeder. Also, it can help in enhancing and designing the correct rating of DT's that can be used for certain loading conditions.

The study will focus on the DT's that are commonly-used and 8116 residential consumers. The study will follow the percent loading for the DT's: $40 \%$ minimum normal loading and $70 \%$ maximum normal loading [4], and the residential power factor is 0.85 [6]. Copper loss and core loss will also be determined in the study. Comparison of the copper loss for overload DT's, under load DT's and 70\% maximum normal loading, will be considered.

\section{A. Data Collection and Instrument}

Data needed for the study such as: number of DT's installed in the feeder with their kVA ratings, consumer connected per DT's were collected by actual mapping or surveying of the feeder. The kWh energy consumption per consumer per month was obtained from the consumers and from DU. The parameters included in the input were the $\mathrm{kVA}$ ratings and the $\mathrm{kWh}$ consumption per consumer per transformer was collected to assess the percent loading of the DT's as seen in figure 8.

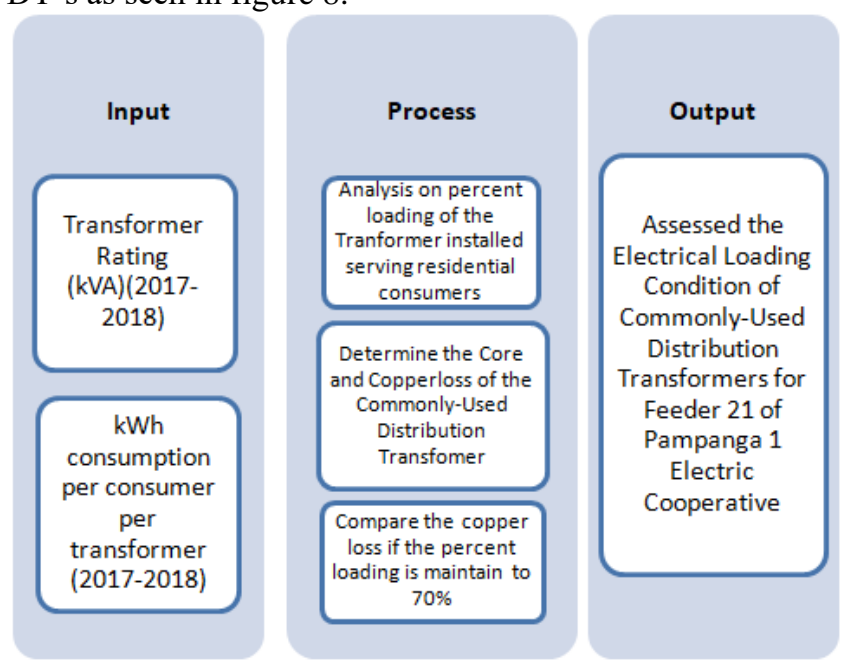

Figure 8: Conceptual Framework of the Study 


\section{METHODOLOGY}

From the data gathered from the actual mapping and from DU, The 104 commonly-used DT's, the number and kWh consumption (January 2017 - December 2018) of consumer connected were used to determine the percent loading per month of the DT by using Microsoft Excel 2013 for using the formula as the standard set in the National Electrification Administration (NEA) System Loss Reduction Manual [14].

$$
\% \text { Loading }=\frac{\text { kWhrDemand }(\text { month })}{\left(\mathrm{KVA}_{\mathrm{TR}}\right)(\mathrm{PF})(\mathbf{7 2 0 H})}
$$

After the percent loading was determined, DT's were classified into three categories:
a. $\quad$ Over Loaded $=71 \%$ and up
b. Normal Loaded $=40 \%$ to $70 \%$
c. Under Loaded $=$ below $40 \%$

When the percent loading has been acquired the kWh per year in terms of core and copper losses will be computed for overloaded, under loaded and $70 \%$ loading by the use of the formula below [14]. Core loss and copper loss in $\mathrm{kW}$ per DT rating used were as follows: 10kVA -0.058 and 0.180 , 15kVA - 0.077 and $0.215,25 \mathrm{kVA}-0.108$ and 0.295, $37.5 \mathrm{kVA}-0.153$ and $0.400,50 \mathrm{kVA}-0.167$ and 0.490 , $75 \mathrm{kVA}-0.275$ and 0.700 , respectively. Then, the value of the losses that were identified will be used to determine if utility can save energy by subtracting the copper losses and the $70 \%$ loading copper losses.

$$
\text { CoreLosses } \frac{k W h r}{y e a r}=(\text { kWcore })(8760 H)
$$

Copper (Cu)Losses $($ kWhr $) /$ year

$=(k W @ 100 \%$ load $)(\% \text { loading })^{2}(8760 H)$

\section{RESULTS \& DISCUSION}

From the 104 commonly-used DT's, 31 of this were found to be under loaded and 30 units were over loaded. Figure 9 shows the graph of the below $40 \%$ loading under loaded DT's. The graph of the percent loading of the DT's and the minimum normal percent loading indicates that there is a wider allocation from the DT's in this condition.

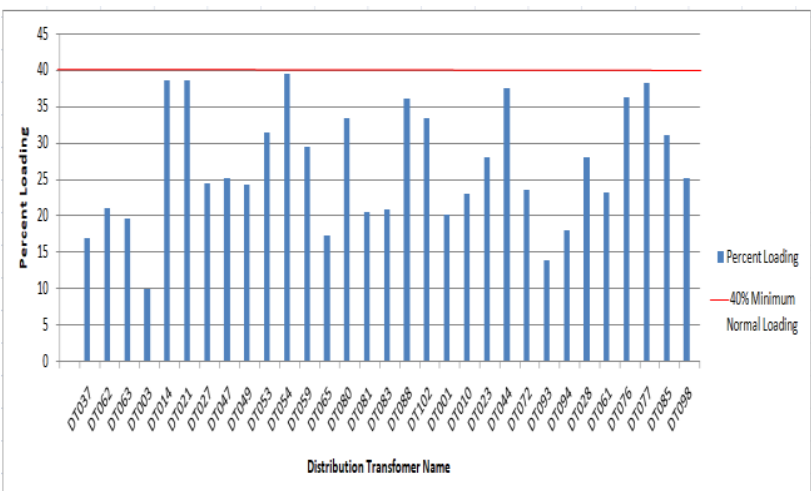

Figure 9: Graphical representation of under loaded DT's

The graphical representations of the DT's in 71\% loading above or overload conditions are shown in figure 10 . The gap between the percent loadings of DT's between the maximum normal loadings exceeds. Some of the DT's were beyond $200 \%$ percent loading which may leads to loss of utilization life of the DT's and the occurrence of power outage.

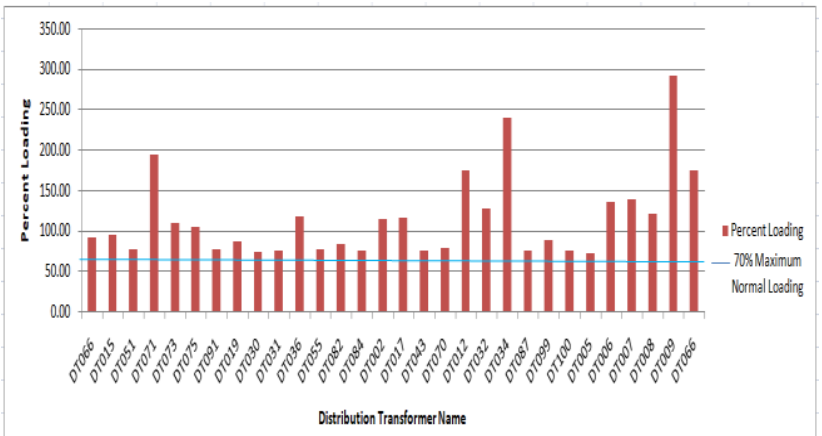

Figure 10: Graphical representation of over loaded DT's From the 31 units of DT's in under loaded conditions, 3 units of 15kVA, 15 units of 25kVA, 7 units of 37.5kVA, 6 units of 50kVA, and from the 30 units of DT's in overloaded conditions, 1 unit of 10kVA, 7 units of 15kVA, 7 units of $25 \mathrm{kVA}, 4$ units of 37.5kVA, 6 units of 50kVA, and 5 units of $75 \mathrm{kVA}$ as shown in figure 11. With 104 DT's only 53 units of DT's were normal loaded, and a total of 61 units of DT's were under and over loaded. $59 \%$ of the DT's installed must be monitored for proper loading conditions.

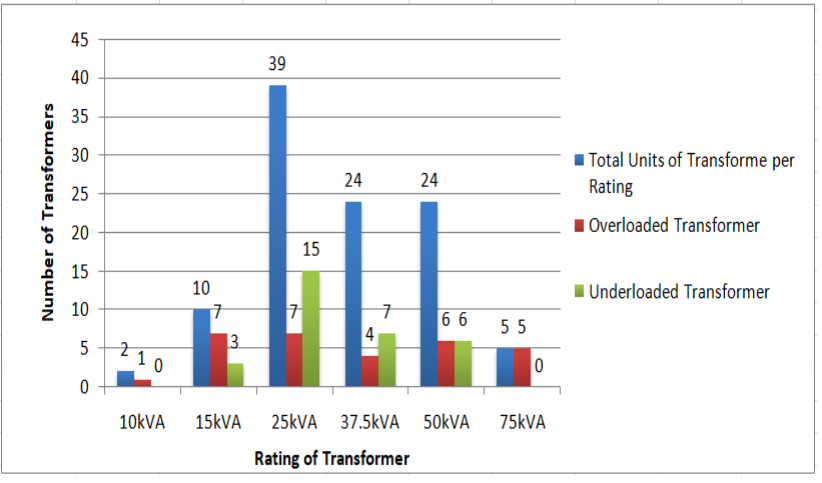

Figure 11: Under Loaded and Overloaded Transformer Figures 12 to 17 shows the graphical representation of the average percent loading per kVA ratings of DT's from January 2017 to December 2018. Also, the graphical comparison of the under loaded, overloaded, minimum normal loading of $40 \%$ and maximum normal loading of $70 \%$ of DT's were indicate to represents the behavior of the percent loading of DT's.

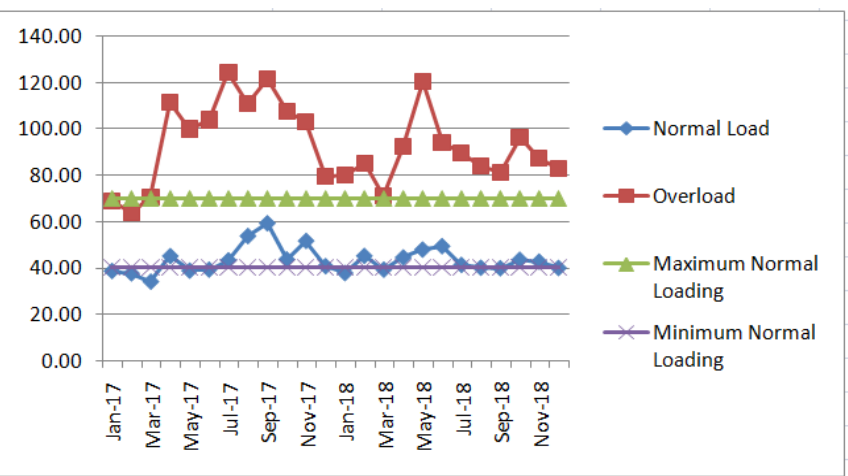

Figure 12: Graphical representation of the Percent Loading of 10kVA Transformer

Published By:

Blue Eyes Intelligence Engineering \& Sciences Publication 


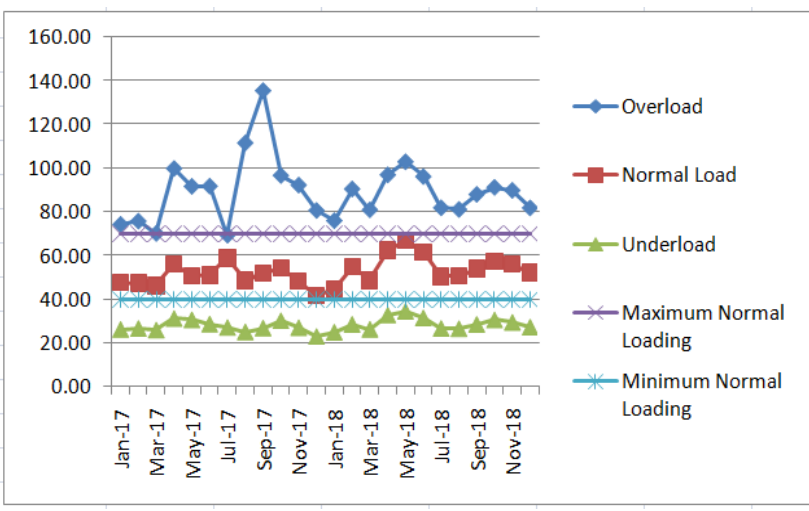

Figure 13: Graphical representation of the Percent Loading of 15kVA Transformer

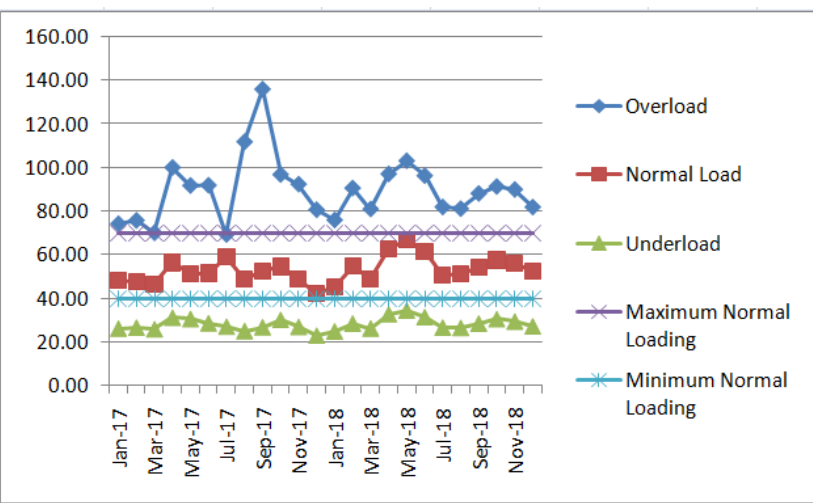

Figure 14: Graphical representation of the Percent Loading of 25kVA Transformer

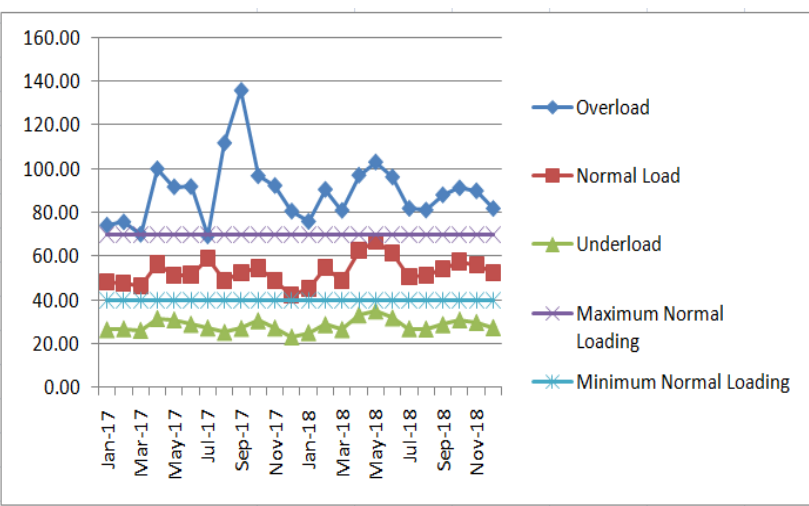

Figure 15: Graphical representation of the Percent Loading of 37.5kVA Transformer

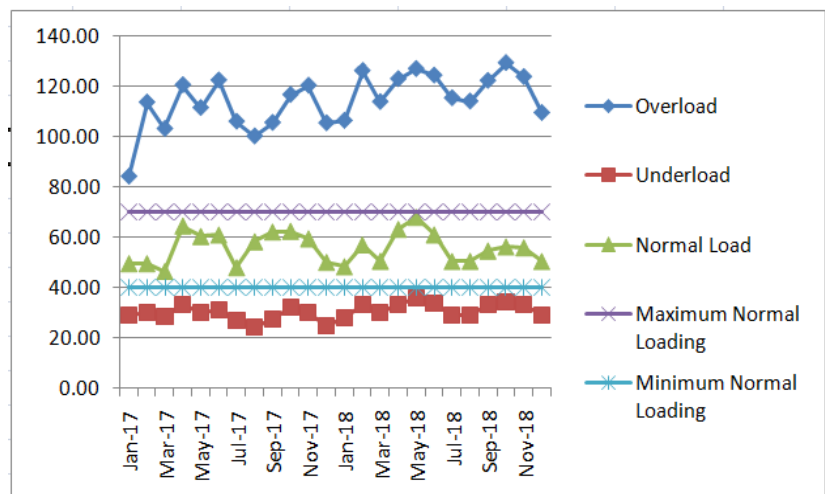

Figure 16: Graphical representation of the Percent Loading of 50kVA Transformer

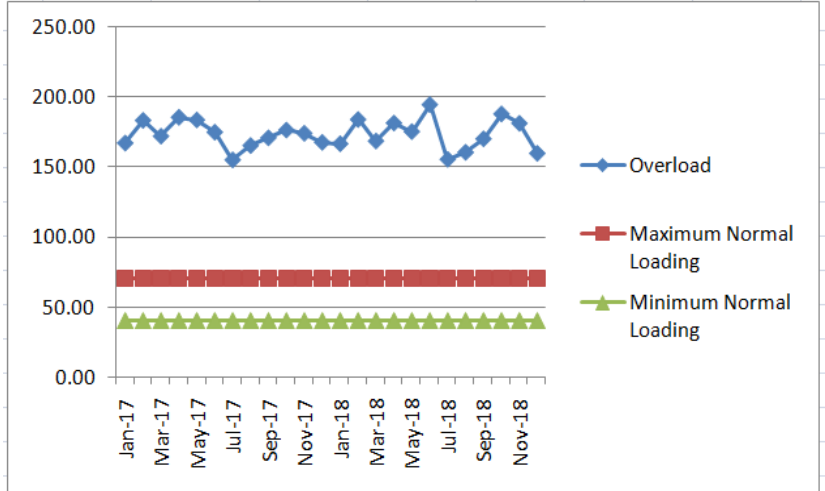

Figure17: Graphical representation of the Percent Loading of 75kVA Transformer

Figures 12 to 17 DT's in each rating shows the same trends in the past two years, when a DT reached a state loading such as underloaded, normal loaded and overloaded it will retain on that situation. For the underloaded conditions as show DT utilization is not maximize while in the case of overloaded losses will increase and the useful life of the DT's is at risk and power failure may occur. And most of the DT's as seen that in the months of April to September of 2017 and 2018 increasing percent loading were experienced.

Core loss, copper loss, maintained 70\% normal loading copper loss and the comparison of the copper loss in terms of $\mathrm{kWh}$ per year of each DT's in under loaded conditions were shown in Table 1. In the situation of underloaded as seen in Table 1, core loss of each DT's was maximized while in terms of copper loss were not fully utilized. Also, some of the DT's does not attained half of the value of the normal loading conditions.

Table 1: Under Loaded DT Losses

\begin{tabular}{|l|c|c|c|c|c|}
\hline No & $\begin{array}{c}\text { DT } \\
\text { Name }\end{array}$ & $\begin{array}{c}\text { Core Loss } \\
\text { (kWh) }\end{array}$ & $\begin{array}{c}\text { CU Loss } \\
\text { (kWh) }\end{array}$ & $\begin{array}{c}\text { CU Loss } \\
\text { at 70\% } \\
\text { (kWh) }\end{array}$ & $\begin{array}{c}\text { CU Loss } \\
\text { Difference }\end{array}$ \\
\hline 1 & DT037 & 674.52 & 53.41 & 922.866 & -869.46 \\
\hline 2 & DT062 & 674.52 & 82.34 & 922.866 & -840.52 \\
\hline 3 & DT063 & 674.52 & 71.51 & 922.866 & -851.35 \\
\hline 4 & DT003 & 946.08 & 25.51 & 1266.258 & -1240.75 \\
\hline 5 & DT014 & 946.08 & 384.39 & 1266.258 & -881.87 \\
\hline 6 & DT021 & 946.08 & 385.37 & 1266.258 & -880.88 \\
\hline 7 & DT027 & 946.08 & 154.63 & 1266.258 & -1111.63 \\
\hline 8 & DT047 & 946.08 & 162.98 & 1266.258 & -1103.28 \\
\hline 9 & DT049 & 946.08 & 151.35 & 1266.258 & -1114.91 \\
\hline 10 & DT053 & 946.08 & 254.51 & 1266.258 & -1011.75 \\
\hline 11 & DT054 & 946.08 & 401.48 & 1266.258 & -864.78 \\
\hline 12 & DT059 & 946.08 & 224.09 & 1266.258 & -1042.17 \\
\hline 13 & DT065 & 946.08 & 76.63 & 1266.258 & -1189.63 \\
\hline 14 & DT080 & 946.08 & 287.83 & 1266.258 & -978.43 \\
\hline 15 & DT081 & 946.08 & 107.04 & 1266.258 & -1159.21 \\
\hline 16 & DT083 & 946.08 & 112.55 & 1266.258 & -1153.71 \\
\hline 17 & DT088 & 946.08 & 335.07 & 1266.258 & -931.19 \\
\hline 18 & DT102 & 946.08 & 288.50 & 1266.258 & -977.76 \\
\hline 19 & DT001 & 1340.28 & 141.45 & 1716.96 & -1575.51 \\
\hline 20 & DT010 & 1340.28 & 183.18 & 1716.96 & -1533.78 \\
\hline 21 & DT023 & 1340.28 & 275.39 & 1716.96 & -1441.57 \\
\hline 22 & DT044 & 1340.28 & 490.25 & 1716.96 & -1226.71 \\
\hline 23 & DT072 & 1340.28 & 193.17 & 1716.96 & -1523.79 \\
\hline 24 & DT093 & 1340.28 & 67.63 & 1716.96 & -1649.33 \\
\hline 25 & DT094 & 1340.28 & 112.68 & 1716.96 & -1604.28 \\
\hline 26 & DT028 & 1462.92 & 334.95 & 2103.276 & -1768.33 \\
\hline 27 & DT061 & 1462.92 & 228.79 & 2103.276 & -1874.48 \\
\hline & & & & & \\
\hline
\end{tabular}




\begin{tabular}{|l|l|l|l|l|l|}
\hline 28 & DT076 & 1462.92 & 564.72 & 2103.276 & -1538.56 \\
\hline 29 & DT077 & 1462.92 & 625.78 & 2103.276 & -1477.50 \\
\hline 30 & DT085 & 1462.92 & 412.43 & 2103.276 & -1690.85 \\
\hline 31 & DT098 & 1462.92 & 269.21 & 2103.276 & -1834.06 \\
\hline
\end{tabular}

Table 2 shows the kWh per year of core loss, copper loss, maintained $70 \%$ normal loading copper loss and the comparison of the copper loss of each DT's in overloaded conditions. Over loaded conditions of each DT's in Table 2, the core loss was fully utilized but in copper loss it exceeded the normal $\mathrm{kWh}$ at the normal loading conditions. Some of the DT's operate at most twice the normal value of $\mathrm{kWh}$.

Table 2: Over Loaded DT Losses

\begin{tabular}{|l|l|c|c|c|c|}
\hline No & $\begin{array}{l}\text { DT } \\
\text { Name }\end{array}$ & $\begin{array}{l}\text { Core Loss } \\
\text { (kWh) }\end{array}$ & $\begin{array}{l}\text { CU Loss } \\
\text { (kWh) }\end{array}$ & $\begin{array}{l}\text { CU Loss at } \\
\text { 70\% (kWh) }\end{array}$ & $\begin{array}{l}\text { CU Loss } \\
\text { Difference }\end{array}$ \\
\hline 1 & DT066 & 508.08 & 1358.73 & 772.63 & 586.10 \\
\hline 2 & DT015 & 674.52 & 1761.66 & 922.87 & 838.79 \\
\hline 3 & DT051 & 674.52 & 1148.07 & 922.87 & 225.21 \\
\hline 4 & DT071 & 674.52 & 7181.43 & 922.87 & 6258.56 \\
\hline 5 & DT073 & 674.52 & 1168.60 & 922.87 & 245.73 \\
\hline 6 & DT075 & 674.52 & 2322.04 & 922.87 & 1399.18 \\
\hline 7 & DT091 & 674.52 & 2102.49 & 922.87 & 1179.63 \\
\hline 8 & DT019 & 674.52 & 1435.95 & 922.87 & 513.09 \\
\hline 9 & DT030 & 946.08 & 1469.42 & 1266.26 & 203.16 \\
\hline 10 & DT031 & 946.08 & 1507.57 & 1266.26 & 241.31 \\
\hline 11 & DT036 & 946.08 & 3656.87 & 1266.26 & 2390.61 \\
\hline 12 & DT055 & 946.08 & 1574.67 & 1266.26 & 308.41 \\
\hline 13 & DT082 & 946.08 & 1853.04 & 1266.26 & 586.78 \\
\hline 14 & DT084 & 946.08 & 1506.24 & 1266.26 & 239.98 \\
\hline 15 & DT002 & 946.08 & 3484.57 & 1266.26 & 2218.31 \\
\hline 16 & DT017 & 1340.28 & 4748.26 & 1716.96 & 3031.30 \\
\hline 17 & DT043 & 1340.28 & 2048.77 & 1716.96 & 331.81 \\
\hline 18 & DT070 & 1340.28 & 2223.91 & 1716.96 & 506.95 \\
\hline 19 & DT012 & 1340.28 & 10823.14 & 1716.96 & 9106.18 \\
\hline 20 & DT032 & 1462.92 & 7051.29 & 2103.28 & 4948.02 \\
\hline 21 & DT034 & 1462.92 & 24716.62 & 2103.28 & 22613.34 \\
\hline 22 & DT087 & 1462.92 & 2537.51 & 2103.28 & 434.24 \\
\hline 23 & DT099 & 1462.92 & 3496.06 & 2103.28 & 1392.79 \\
\hline 24 & DT100 & 1462.92 & 2563.11 & 2103.28 & 459.83 \\
\hline 25 & DT005 & 1462.92 & 2297.18 & 2103.28 & 193.90 \\
\hline 26 & DT006 & 2409 & 11548.83 & 3004.68 & 8544.15 \\
\hline 27 & DT007 & 2409 & 11975.42 & 3004.68 & 8970.74 \\
\hline 28 & DT008 & 2409 & 9067.11 & 3004.68 & 6062.43 \\
\hline 29 & DT009 & 2409 & 52343.39 & 3004.68 & 49338.71 \\
\hline 30 & DT066 & 2409 & 18790.56 & 3004.68 & 15785.88 \\
\hline & & & & & \\
\hline
\end{tabular}

The summary of the core loss, copper loss, copper loss at $70 \%$ loading condition and the difference in copper loss in MWh per year are shown in table 3 . The difference in copper loss was attained by subtracting the copper loss and copper loss at $70 \%$ loading condition.

Table 3: Summary of Losses

\begin{tabular}{|l|c|c|c|c|}
\hline Loading & $\begin{array}{c}\text { Core Loss } \\
\text { (MWh) }\end{array}$ & $\begin{array}{c}\text { CU Loss } \\
\text { (MWh) }\end{array}$ & $\begin{array}{c}\text { CU Loss at } \\
\mathbf{7 0 \%} \\
\text { (MWh) }\end{array}$ & $\begin{array}{c}\text { CU Loss } \\
\text { Difference }\end{array}$ \\
\hline Under Loaded & 34.37 & 7.46 & 46.40 & -38.94 \\
\hline Over Loaded & 38.04 & 199.76 & 50.61 & 149.15 \\
\hline Total & & $\mathbf{1 1 0 . 2 1}$ \\
\hline
\end{tabular}

\section{CONCLUSION}

From the 2017-2018 data, percent loading of Feeder 21 distribution transformer, 30 units of DT's are overloaded, and 31 units of DT's are under loaded. A total of 61 units out of 104 units or $59 \%$ of commonly-used transformers must be taken into consideration.

The total core loss, copper loss, copper loss at $70 \%$ loading and the copper loss difference of the under loaded DT's were 34.37MWh, 7.46MWh, 46.4MWh and -38.94MWh. On the other hand, the total core loss, copper loss, copper loss at 70\% loading and the copper loss difference of the overloaded DT's are 38.04MWh, 199.76MWh, 50.61MWh and 149.15MWh. By maintaining the percent loading to $70 \%$ the copper loss due to the 61 units of DT's can be saved up to $110.21 \mathrm{MWh}$ per year. With a proper monitoring of the percent loading of the DT's, reduce the copper loss and maximize its utilization life.

\section{RECOMMEDATIONS}

Monitoring of distribution transformer is vital for the operation of distribution utility. A proper rating of the transformer must be installed per feeder to lessen the system loss it contributes. Proper load centering can also be considered to utilize the consumer coverage of the distribution transformer fully. Even the number of consumers per transformer must be regarded as for the percent loading. Relocation of consumers per transformer may be taken for considerations.

\section{REFERENCES}

1. M. A. Sahagun, A. Tolentino, and R. Gomez Jr., (2018). Assessment and Forecasting of Electric Load Demand of Don Honorio Ventura Technological University, 2018 IEEE, Humanoid, Nanotechnology, Information Technology, Communication and Control, Environment, and Management(HNICEM)

2. Philippine Distribution Code, Performance Standards Distribution and Supply, (2001), Energy Regulatory Commission (ERC), (pp 29-37)

3. A. K. and B. L. Theraja, A Textbook of Electrical Technology in S.I. Units Volume II, (2005). (pp1116-1206).

4. Electric Cooperative's Distribution Utility Manual (August 2009) RetrievedonSeptember11,2018,fromhttp://www.gmcdmc.ph/pdf_files_ dmc/ECDU\%20Planning\%20Manual\%2010Aug2009.pdf

5. M. Teng Au, T. Anthony, N. Kamaruddin*, R. Verayiah, S. A. Mustaffa and M. Yusoff, (2008), A Simplified Approach in Estimating Technical Losses in Distribution Network Based on Load Profile and Feeder Characteristics, 2nd IEEE International Conference on Power and Energy (PECon 08), December 1-3, 2008, Johor Baharu, Malaysia

6. National Electrification Administration (NEA) and Japan International Cooperative Agency (JICA), Electric Cooperatives System Loss Reduction Manual, Identifying Countermeasures against Technical Losses for the Low Voltage System, (2013), (pp29-76).W.-K. Chen, Linear Networks and Systems (Book style). Belmont,

CA: Wadsworth, 1993, pp. 123-135.

7. Ali Arefi, Mahmood-reza Haghifam, Akbar Yavartalab, Javad Olamaei and Hessam Keshtar (2009), Loss Reduction Planning in Electric Distribution Networks of Iran, Retrieved on June 19, 2019fromhttp://0ieeexplore.ieee.org.lib1000.dlsu.edu.ph/stamp/stamp.j sp?tp=\&arnumber $=05876386$.

8. WFu, J McCalley, V Vittal, (2001), Risk Assessment for Transformer Loading, IEEE TRANSACTIONS ON POWER SYSTEMS, VOL. 16, NO. 3, AUGUST 2001H. Poor, An Introduction to Signal Detection and Estimation. New York: Springer-Verlag, 1985, ch. 4.

9. N.Pandit1, R.L.Chakrasali, (2017), Distribution Transformer Failure in India Root Causes and Remedies, International Conference on Innovative Mechanisms for Industry Applications (ICIMIA 2017).

10. Defu Cai, Wenna Wang, Xianjun Ma, Min Xu, Zhenting He, Zeyang Tang, Chu Zhou, Na Han, Ying Wang , (2018), Analysis of Heavy load and Overload Distribution Transformer in Regional Power Grid

11. C.-s. Chen , T.-t. Ku , C.-h. Lin , Implementation of a systematic distribution transformer load management in Taipower , (2009), IET Generation, Transmission \& Distribution , Volume: 3, Issue: 3

12. M. Li, Q. Zhou, SMIEEE, and Z. Yang , (2015), Distribution transformer mid-term heavy load and overload pre-warning based on logistic regression

13. C SchaubDr. Raleigh, Power Loss Management for Restructured Utility Environment Second Edition by Booth and Associates, Inc. 1101 NC 27606, 2004. 
14. National Electrification Administration, System Loss Reduction Manual, DX3430, (1993), Engineering Bulletin. National Electrification Administration (pp1-61).

\section{AUTHORS PROFILE}

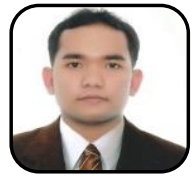

Reynaldo H. Gomez Jr. is a Registered Electrical Engineer, Registered Master Electrician and Licensed Professional Teacher. A faculty of Electrical Engineering Department of Don Honorio Ventura State University (DHVSU). He is a graduate of Master of Engineering Program Major in Electrical Engineering (MEP-EE) at Holy Angel University (HAU) and currently pursuing his Doctor of Philosophy in Engineering Management (PhD. EnM) at Nueva Ecija University of Science and Technology (NEUST). Member of Institute of Integrated Electrical Engineers. His research works focuses mostly in electrical power system monitoring, electrical distribution analysis, electrical system designing, power system protection and relaying.

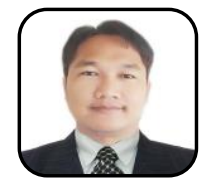

Edgardo M. Santos. Chairperson, Electrical Engineering Department of Don Honorio Ventura State University (DHVSU). A Licensed Electrical Engineer, Master Electrical, Master Plumber, Professional Teacher and rank number 7 for the September 2007 Registered Master Electrician Board Examinations. A Graduate of Doctor of Philosophy in Engineering Management (PhD. EnM) at Nueva Ecija University of Science and Technology (NEUST). A senior member of Institute on Integrated Electrical Engineers. Electrical System Design, High Rise Building Designs and renewable energies are his field of research.

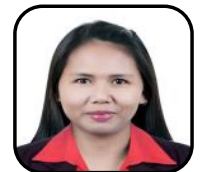

Armie C. Tolentino. Faculty, Electrical Engineering Department of Don Honorio Ventura State University (DHVSU). Research Coordination of College of Engineering and Architecture of DHVSU. A Registered Electrical Engineering and Licensed Professional Teacher. A graduate of Master of Engineering Program Major in Electrical Engineering (MEP-EE) at Holy Angel University (HAU). Member of Institute of Integrated Electrical Engineers. Her research field of work mostly focus in renewable energy and electrical power efficiency.



Eldren V. Bulanan. Health and Safety Section Head of Pampanga I Electric Cooperative (PELCO I). A licensed Electrical Engineer and Professional Teacher. Current enrolled at Nueva Ecija University of Science and Technology (NEUST) with a degree of Master of Engineering Management (MEnM). He focuses in power system operations and safety.

Noel T. Florencondia. Dean of the College of



Engineering of Nueva Ecija University of Science and Technology (NEUST). A Professional Electrical Engineer (PEE) and Graduate of Doctor of Philosophy in Engineering Management (PhD. EnM) at Nueva Ecija University of Science and Technology (NEUST). A member of Institute on Integrated Electrical Engineers. Electrical System Design, High Rise Building Designs and Arc Flashes are his field of research. 